\title{
Long-term outcomes after lobectomy for non-small cell lung cancer when unsuspected pN2 disease is found: A National Cancer Data Base analysis
}

\author{
Chi-Fu Jeffrey Yang, MD, ${ }^{a}$ Arvind Kumar, ${ }^{a}$ Brian C. Gulack, MD, ${ }^{a}$ Michael S. Mulvihill, MD, \\ Matthew G. Hartwig, MD, ${ }^{a}$ Xiaofei Wang, PhD, ${ }^{b}$ Thomas A. D'Amico, MD, and \\ Mark F. Berry, MD, MHS
}

\begin{abstract}
Objective: There are few studies evaluating whether to proceed with planned resection when a patient with non-small cell lung cancer (NSCLC) unexpectedly is found to have $\mathrm{N} 2$ disease at the time of thoracoscopy or thoracotomy. To help guide management of this clinical scenario, we evaluated outcomes for patients who were upstaged to $\mathrm{pN} 2$ after lobectomy without induction therapy using the National Cancer Data Base (NCDB).
\end{abstract}

Methods: Survival of NSCLC patients treated with lobectomy for clinically unsuspected mediastinal nodal disease (cT1-cT3 cN0-cN1, pN2 disease) from 1998-2006 in the NCDB was compared with "suspected" N2 disease patients (cT1-cT3 cN2) who were treated with chemotherapy with or without radiation followed by lobectomy, using matched analysis based on propensity scores.

Results: Unsuspected pN2 disease was found in $4.4 \%$ of patients (2047 out of $46,691)$ who underwent lobectomy as primary therapy for cT1-cT3 cN0-cN1 NSCLC. The 5-year survival was $42 \%, 36 \%, 21 \%$, and $28 \%$ for patients who underwent adjuvant chemotherapy $(\mathrm{n}=385)$, chemoradiation $(\mathrm{n}=504)$, radiation $(\mathrm{n}=300)$, and no adjuvant therapy $(\mathrm{n}=858)$, respectively. Five-year survival of the entire unsuspected pN2 cohort was worse than survival of 2302 patients who were treated with lobectomy after induction therapy for clinical N2 disease $(30 \%$ vs $40 \% ; P<.001)$, although no significant difference in 5 -year survival was found in a matched-analysis of 655 patients from each group $(37 \%$ vs $37 \% ; P=.95)$.

Conclusions: This population-based analysis suggests that, in the setting of unsuspected pN2 NSCLC, proceeding with lobectomy does not appear to compromise outcomes if adjuvant chemotherapy with or without radiation therapy can be administered following surgery. (J Thorac Cardiovasc Surg 2016;151:1380-8)

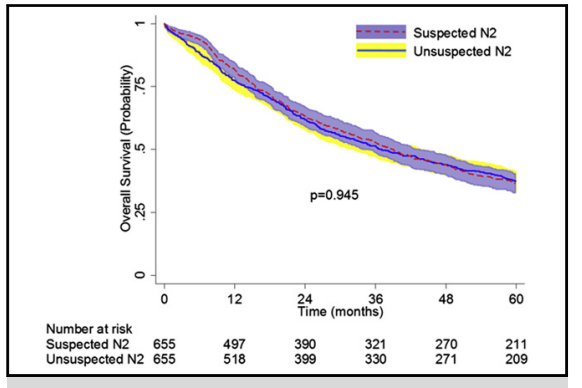

Survival of unsuspected pN2 versus clinical stage IIIA N2 non-small cell lung cancer patients: Matched-analysis.

\section{Central Message}

Aborting planned lobectomy to administer chemotherapy before resection is not mandatory in the setting of unsuspected pN2 NSCLC.

\section{Perspective}

Outcomes of patients with cT1-cT3 cN0-N1 NSCLC found to have $\mathrm{pN} 2$ disease during resection are not well characterized. A matched-analysis based on propensity scores of the National Cancer Data Base showed no significant difference in survival between patients with unsuspected pN2 who received lobectomy and those with clinical N2 NSCLC who received induction therapy before lobectomy.

See Editorial Commentary page 1389.

See Editorial page 1235.
The practice of treating with induction therapy before potential surgery for patients with non-small cell lung cancer (NSCLC) who have pathologically confirmed N2 disease is well supported in the literature. ${ }^{1}$ However, there are few studies evaluating whether to proceed with planned

From the ${ }^{\mathrm{a}}$ Department of Surgery, Duke University Medical Center, and ${ }^{\mathrm{b}}$ Department of Biostatistics, Duke University, Durham, NC; and ${ }^{\mathrm{c}}$ Department of Cardiothoracic Surgery, Stanford University Medical Center, Stanford, Calif.

Supported by the National Institutes of Health-funded Cardiothoracic Surgery Trials Network (grant No. 5U01HL088953-05 to M.G.H) and by an American College of Surgeons Resident Research Scholarship (to C.J.Y).

Read at the 95th Annual Meeting of The American Association for Thoracic Surgery, Seattle, Washington, April 25-29, 2015. resection when a patient unexpectedly is found to have N2 disease at the time of thoracoscopy or thoracotomy. This clinical scenario has been reported to occur in $2.0 \%$ to $18.5 \%$ of patients, ${ }^{2-8}$ and is associated with a 5-year overall survival ranging from $10 \%$ to $40 \% .^{2,4,6,9-12}$

Received for publication April 27, 2015; revisions received Oct 12, 2015; accepted for publication Dec 11, 2015; available ahead of print Feb 11, 2016. Address for reprints: Mark F. Berry, MD, MHS, Falk Cardiovascular Research Center, 300 Pasteur Dr, Stanford, CA 94305 (E-mail: berry037@stanford.edu). $0022-5223 / \$ 36.00$

Copyright (C) 2016 by The American Association for Thoracic Surgery http://dx.doi.org/10.1016/j.jtcvs.2015.12.028 


\section{Abbreviations and Acronyms \\ CDCC $=$ Charlson/Deyo comorbidity score \\ $\mathrm{CT}=$ computed tomography \\ $\mathrm{NCDB}=$ National Cancer Data Base \\ NSCLC $=$ non-small cell lung cancer \\ PET = positron emission tomography}

Scanning this QR code will take you to the article title page.

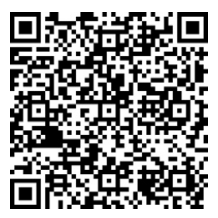

Some reports, ${ }^{2,6,9-11,13}$ including those by the National Comprehensive Cancer Network and the American College of Chest Physicians, ${ }^{14,15}$ have suggested that the proper course of action for patients with unsuspected $\mathrm{N} 2$ disease diagnosed at the time of surgery is to continue with resection, although this guideline is based on very limited data and noted to be a Grade $2 \mathrm{C}$ recommendation. ${ }^{15}$ Other authors have suggested a preference toward aborting resection to administer induction therapy. ${ }^{16}$

To improve the level of evidence available to guide treatment decisions regarding unsuspected $\mathrm{N} 2$ disease, we evaluated survival of patients with unsuspected N2 NSCLC who underwent lobectomy using the National Cancer Data Base (NCDB).

\section{METHODS}

Data for this study were queried from the NCDB, which is jointly sponsored by the American College of Surgeons Commission on Cancer and the American Cancer Society. With data from more than 30 million patients and 1500 cancer centers in the United States, this database contains information on approximately $70 \%$ of all newly diagnosed cases of cancer in the United States and Puerto Rico. ${ }^{17}$ Clinical staging information was directly recorded in the NCDB using American Joint Committee on Cancer sixth edition TNM classifications for the years of study inclusion $(1998-2006){ }^{18}$

\section{Study Design}

This NCDB analysis was approved by the Institutional Review Board of Duke University. From a de-identified NCDB participant user file, all NSCLC patients in the NCDB who were treated with lobectomy without induction therapy for unsuspected $\mathrm{N} 2$ disease (cT1-T3 cN0-cN1 cM0 but pathologic $\mathrm{N} 2$ disease) were selected using the International Classification of Diseases for Oncology, 3rd edition histology and topography codes. The time period starting from the beginning of 1998 to the end of 2006 was chosen because long-term survival data for patients diagnosed in this time period were available at the time of our analysis. Patients with nonmalignant pathology, history of previous unrelated malignancy, and unknown survival data were excluded from analysis ( 2 patients in the unsuspected N2 group had missing survival data). To create a comparison group and estimate the influence of proceeding with resection for unsuspected $\mathrm{pN} 2$ versus aborting resection to deliver induction therapy, all patients treated with induction chemotherapy with or without radiation followed by lobectomy for "suspected N2 disease" (cT1-cT3 cN0 cM0) were also selected. The primary outcome measured was overall survival. Hospital length of stay and 30-day readmission were secondary outcomes examined as potential surrogate markers for postoperative morbidity, which is not specifically recorded in the NCDB. Data for these secondary outcomes were only recorded for patients from 2003 to 2006 .

\section{Statistical Analysis}

Patients were grouped based on their diagnosis of N2 disease (suspected or unsuspected). Pearson $\chi^{2}$ test for categorical variables and Wilcoxon rank sum test for continuous variables were used to determine differences in patient and treatment characteristics. Survival time was measured from time of diagnosis to time of death or last follow-up, and median survival and 5-year survival were estimated by the Kaplan-Meier product limit approach. The influence of adjuvant therapy on survival of patients in the unsuspected N2 group was evaluated using the Kaplan-Meier method and log-rank test.

Outcomes of patients in the suspected and unsuspected N2 groups were initially compared using the log-rank test. A matched-analysis based on propensity scores was then conducted to create a cohort of patients with unsuspected N2 NSCLC who underwent lobectomy with similar baseline characteristics to patients with suspected N2 disease who underwent induction chemotherapy with or without radiation followed by lobectomy, to attempt to control for nonrandom differences in baseline characteristics between the groups, as previously described. ${ }^{19,20}$ Briefly, patients were stratified into 2 groups based on unsuspected pN2 disease and suspected $\mathrm{cN} 2$ disease and a logistic regression model was used to calculate propensity scores based on patient- and disease-related variables that were determined to most likely act as confounders. These variables were determined a priori and included age, gender, race, Charlson/Deyo comorbidity (CDCC) score, clinical $\mathrm{T}$ status, facility type, insurance type, and histology. Because CDCC score was not available until 2003, the matched-analysis included only patients from 2003 to 2006. The most appropriately matched pairs were selected with a caliper matching algorithm (caliper distance 0.01) with controls used only once. After propensity score matching, differences between groups were assessed using Pearson $\chi^{2}$ tests or Fisher exact test for categorical variables and Student $t$ test for continuous variables. The Kaplan-Meier method was used to compare overall survival from time of surgery to time of death or last follow-up across groups.

The matched-analysis and survival analysis described above were repeated to compare the survival of patients who had surgery plus adjuvant chemotherapy versus patients who received induction chemotherapy followed by surgery. An additional matched analysis was performed to compare the survival of patients who had surgery plus adjuvant chemoradiation versus induction chemoradiation with surgery.

To further evaluate the influence of adjuvant therapies on patients with unsuspected $\mathrm{N} 2$ disease, we performed a multivariable analysis on a subgroup of patients who had undergone complete resection and excluded patients who died within 30 days of lobectomy because these patients most likely did not receive adjuvant therapy, and were excluded from the analysis to prevent selection bias that could overestimate the benefit of adjuvant therapy benefits. For patients with unsuspected N2 disease, a Cox proportional hazards model was used to compare overall survival between groups receiving different adjuvant therapies (eg, adjuvant chemotherapy, chemoradiation, radiation, and no adjuvant therapy), adjusting for age, gender, race, CDCC score, clinical T stage, facility type, insurance type, histology, and tumor location. All covariates included in the model were determined a priori according to clinical relevance.

All statistical analyses were performed using Stata Statistical Software release 13.0 (StataCorp LP, College Station, Tex). 


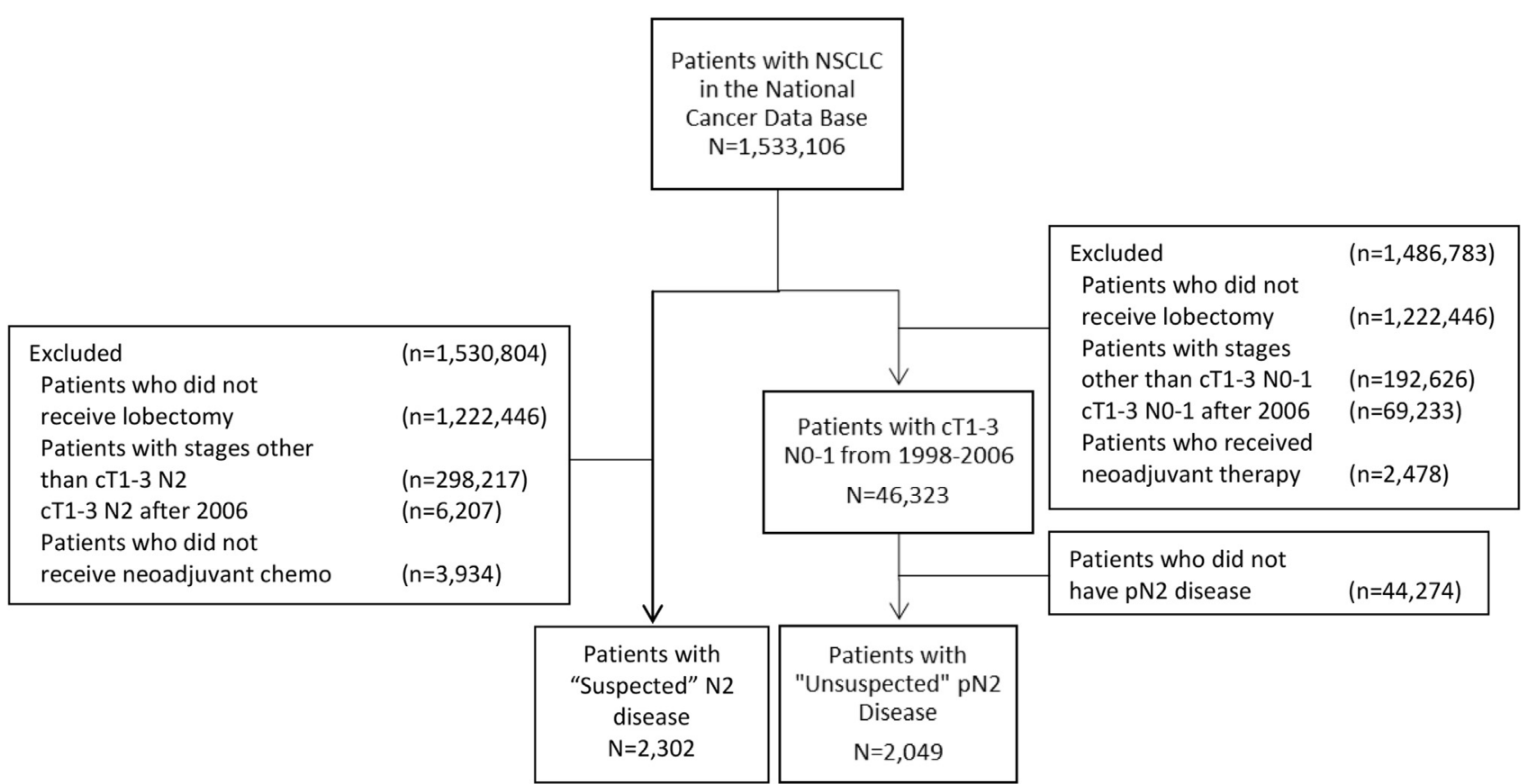

FIGURE 1. Consort diagram showing schema of study subject selection. NSCLC, Non-small cell lung cancer.

\section{RESULTS}

Between 1998 and 2006, 2047 of 46,691 patients (4.4\%) who underwent lobectomy as primary therapy for $\mathrm{cT} 1-\mathrm{cT} 3$ cN0-cN1 cM0 NSCLC had unsuspected pN2 disease after surgical resection (Figure 1). The median survival was 31 months (95\% confidence interval [CI], 29-33 months) and the overall 5-year survival was 30\% (95\% CI, $28 \%$ $32 \%$ ) for the entire unsuspected N2 cohort. In this cohort, no adjuvant therapy was administered for 858 patients $(42 \%)$, whereas adjuvant chemotherapy was given to 385 $(19 \%)$ patients, adjuvant chemoradiation to 504 patients $(25 \%)$, and adjuvant radiation to 300 patients $(15 \%)$. Among patients in this unsuspected N2 group, the 5-year survival was significantly better for patients who received adjuvant chemotherapy (42\% [95\% CI, 36\%-47\%]) or adjuvant chemoradiation (36\% [95\% CI, 31\%-40\%]) compared with patients who received adjuvant radiation (21\% [95\% CI, 16\%-26\%]) and patients who had no adjuvant therapy (28\% [95\% CI, 24\%-31\%]) (Figure 2). Multivariable adjusted survival analyses demonstrated that when compared with no adjuvant therapy, adjuvant chemotherapy (hazard ratio $[\mathrm{HR}], 0.67 ; 95 \% \mathrm{CI}$, $0.55-0.82 ; P<.001)$ and chemoradiation (HR, $0.75 ; 95 \%$ CI, $0.58-0.92 ; P<.001)$ were associated with improved survival, whereas adjuvant radiation treatment alone (HR, $1.14 ; 95 \%$ CI, $0.84-1.56 ; P=.40$ ) was not associated with improved survival.

During the same time period, 2302 patients underwent lobectomy after induction chemotherapy $(\mathrm{n}=898 ; 39 \%)$ or induction chemoradiation $(\mathrm{n}=1404 ; 61 \%)$ for suspected
N2 (cT1-cT3 cN2 cM0) NSCLC (Figure 1). Baseline characteristics and peri- and postoperative data for the unsuspected and suspected groups are detailed in Tables 1 and 2. Patients with unsuspected N2 disease were older, less likely to be men, had a higher CDCC score, and were more likely to be on Medicare or Medicaid than patients with suspected N2 disease. Patients in the unsuspected N2 group also had a lower clinical $\mathrm{T}$ status, were less likely to be treated in a comprehensive community cancer program, and were more likely to have a histology report of adenocarcinoma compared with patients with suspected N2 disease. There were no significant differences between race.

The patients in the unsuspected N2 group had a greater median number of regional lymph nodes examined, and were more likely to have a complete resection. The unsuspected N2 group had a mean \pm standard deviation pathologic tumor size of $3.8 \pm 4.3 \mathrm{~cm}$, whereas the suspected N2 group had a mean \pm standard deviation pathologic tumor size of $4.3 \pm 6.0 \mathrm{~cm}$. Patients with unsuspected N2 disease were less likely to be readmitted within 30 days of surgery, but had a higher mean surgical inpatient stay compared with patients with suspected N2 disease. Differences were also found in pathologic stages between the groups. More patients with unsuspected N2 disease had pathologic stage T2 tumors. All patients in the unsuspected group had $\mathrm{pN} 2$ disease, whereas significant downstaging had occurred in the suspected group, and only $47.9 \%$ continued to have $\mathrm{pN} 2$ disease after surgery. No significant differences were found between the 30-day 


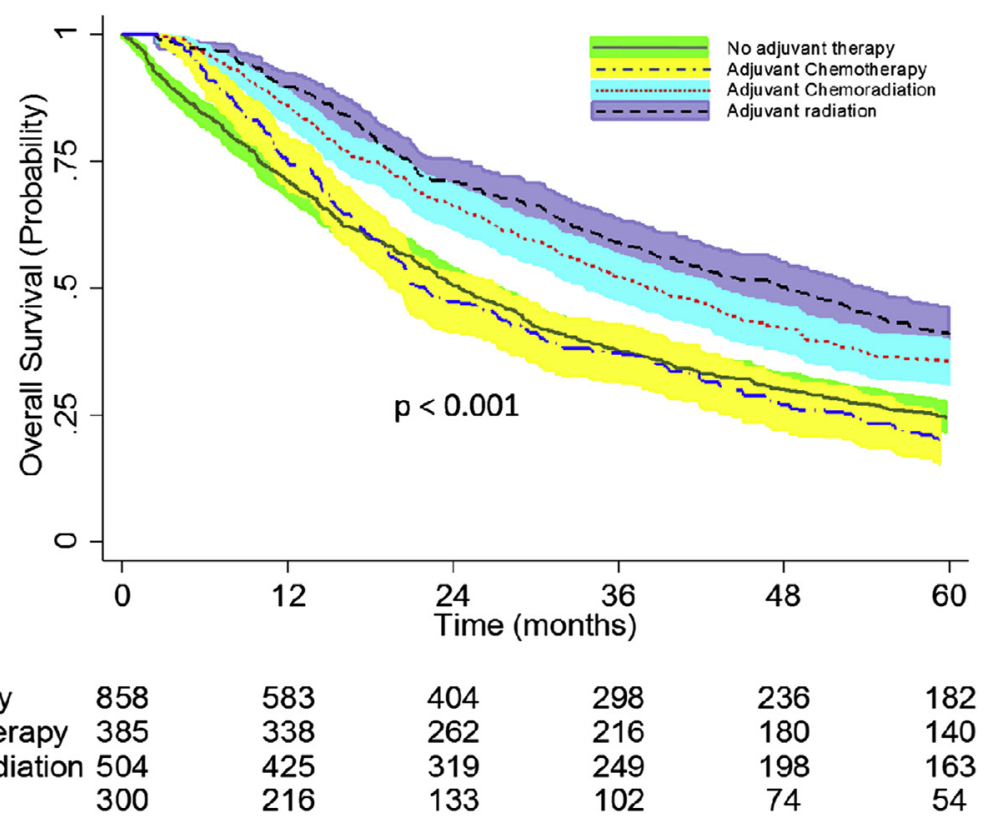

FIGURE 2. Overall survival of patients with unsuspected pN2 disease stratified by type of adjuvant therapy. Patients with "unsuspected N2" disease had undergone lobectomy as primary therapy for clinical T1 to T3 N0 to N1 non-small cell lung cancer and were found to have pN2 disease at the time of surgery. These patients then went on to receive either adjuvant chemotherapy, adjuvant chemoradiation, adjuvant radiation therapy, or no adjuvant therapy.

mortality rates between the 2 groups. However, median survival (31 months [95\% CI, 29-33 months] vs 41 months [95\% CI, 38-44 months]; $P<.001)$ and overall 5-year survival $(30 \%$ [95\% CI, $28 \%-32 \%$ ] vs $40 \%$ [95\% CI, $38 \%-42 \%$ ]; $P<.001)$ was worse for the entire unsuspected $\mathrm{N} 2$ cohort when compared with that of the suspected N2 cohort (Figure 3, A).

\section{Unsuspected N2 NSCLC Versus Suspected N2 NSCLC: Matched Analysis}

Propensity matching created a population of 655 patients with unsuspected $\mathrm{N} 2$ disease who underwent lobectomy and 655 patients with suspected $\mathrm{N} 2$ disease who underwent induction chemotherapy with or without radiation followed by lobectomy. Table 3 shows that there were no significant differences between the preoperative characteristics for the 2 groups after matching. Of the 655 patients from the unsuspected $\mathrm{N} 2$ group, adjuvant chemotherapy was given to 203 patients $(31.0 \%)$, and adjuvant chemoradiation was given to 181 patients $(27.6 \%)$. The 30 -day mortality rates of the patients with unsuspected $\mathrm{N} 2$ disease $(1.8 \%$; $\mathrm{n}=12)$ and those with suspected $\mathrm{N} 2$ disease $(2.6 \%$; $\mathrm{n}=17)$ were not significantly different $(P=.35)$. There were also no significant differences in median survival (39 months [95\% CI, 35-43 months] vs 37 months [ $95 \%$ CI, 32-44 months]) and overall 5-year survival (37\% [95\% CI, 33-40 months] vs 37\% [95\% CI, 34-41 months]) between patients with unsuspected $\mathrm{N} 2$ disease and patients with suspected $\mathrm{N} 2$ disease (Figure 3, B).
Differences in peri- and postoperative outcomes between these 2 groups are detailed in Table 4.

Two subgroup analyses were performed. First, a matched analysis using propensity scores comparing patients with unsuspected $\mathrm{N} 2$ disease who underwent lobectomy and adjuvant chemotherapy to patients with suspected N2 disease who underwent induction chemotherapy and lobectomy created 2 cohorts of 219 patients. There were no significant differences in baseline characteristics between the 2 groups (data not shown). There was no significant difference in overall 5-year survival between the unsuspected and suspected $\mathrm{N} 2$ groups $(40 \%$ [95\% CI, 33-46 months] vs $35 \%$ [95\% CI, 28-41 months]; $P=.54)$, respectively.

In the second subgroup analysis, a matched analysis created a population of 201 patients with unsuspected N2 disease who underwent lobectomy and adjuvant chemoradiation and a population of 201 patients with suspected N2 disease who underwent induction chemoradiation followed by lobectomy. The 5-year survival of these patients with unsuspected N2 disease (38\% [95\% CI, 32\%-45\%]) was significantly higher than those with suspected $\mathrm{N} 2$ disease $(30 \% \quad[95 \%$ CI, 24\%-37\%]; $P=.014)$.

\section{DISCUSSION}

In our population-based analysis, we found that the incidence of unsuspected $\mathrm{pN} 2$ disease of patients undergoing lobectomy for cT1-cT3 cN0-N1 cM0 NSCLC was $4.4 \%$. 
TABLE 1. Preoperative demographic and clinical characteristics

\begin{tabular}{|c|c|c|c|}
\hline & $\begin{array}{c}\text { Unsuspected } \\
\text { N2 } \\
(\mathbf{n}=\mathbf{2 0 4 7}) \\
\end{array}$ & $\begin{array}{c}\text { Suspected } \\
\quad \mathrm{N} 2 \\
(\mathrm{n}=\mathbf{2 3 0 2}) \\
\end{array}$ & $\begin{array}{c}P \\
\text { value }^{*} \\
\end{array}$ \\
\hline Patient age (y) & & & $<.01$ \\
\hline Mean \pm standard deviation & $66.4 \pm 10.3$ & $61.7 \pm 9.7$ & \\
\hline Median (interquartile range) & $67(60-74)$ & $62(55-69)$ & \\
\hline Sex & & & $<.01$ \\
\hline Male & 939 (45.9) & $1191(51.7)$ & \\
\hline Female & $1108(54.1)$ & $1111(48.3)$ & \\
\hline Race & & & .22 \\
\hline White & $1795(87.7)$ & $2050(89.1)$ & \\
\hline Black & $157(7.7)$ & $168(7.3)$ & \\
\hline Other & $95(4.6)$ & $84(3.7)$ & \\
\hline Charlson/Deyo score & & & $<.01$ \\
\hline 0 & $600(58.5)$ & $1010(71.4)$ & \\
\hline 1 & $325(31.7)$ & $335(23.7)$ & \\
\hline 2 & $100(9.8)$ & $70(5.0)$ & \\
\hline Insurance status & & & $<.01$ \\
\hline Uninsured & $26(1.3)$ & $42(1.9)$ & \\
\hline Private & $808(40.3)$ & $1179(52.5)$ & \\
\hline Medicare/aid & $1093(54.5)$ & $907(40.4)$ & \\
\hline Other government & $69(3.4)$ & $92(4.1)$ & \\
\hline Unknown & $11(0.6)$ & $24(1.1)$ & \\
\hline Clinical $\mathrm{T}$ status & & & $<.01$ \\
\hline 1 & $988(48.3)$ & $670(29.1)$ & \\
\hline 2 & $1010(49.3)$ & $1282(55.7)$ & \\
\hline 3 & $49(2.4)$ & $350(15.2)$ & \\
\hline Facility type & & & .02 \\
\hline Community cancer program & $163(8.0)$ & $161(7.0)$ & \\
\hline $\begin{array}{l}\text { Comprehensive community } \\
\text { cancer program }\end{array}$ & $965(47.1)$ & $1,138(49.4)$ & \\
\hline Academic/research program & $854(41.7)$ & $959(41.7)$ & \\
\hline $\begin{array}{l}\text { Other specified types of } \\
\text { cancer programs }\end{array}$ & $65(3.2)$ & $44(1.9)$ & \\
\hline Histology & & & $<.01$ \\
\hline Adenocarcinoma & $1194(58.4)$ & $1015(44.1)$ & \\
\hline Squamous & $388(19.0)$ & $602(26.2)$ & \\
\hline Large cell & $100(4.9)$ & $139(6.0)$ & \\
\hline Bronchioalveloar & $123(6.0)$ & $45(2.0)$ & \\
\hline Neuroendocrine & $30(1.5)$ & $11(0.5)$ & \\
\hline Other & $209(10.2)$ & $489(21.3)$ & \\
\hline
\end{tabular}

Values are presented as $\mathrm{n}(\%)$ unless otherwise noted. $* P$ values are from Wilcoxon rank sum test on continuous variables and from $\chi^{2}$ test on categorical variables.

The overall 5-year survival of this entire unsuspected $\mathrm{N} 2$ cohort was $30 \%$. Among patients in this unsuspected $\mathrm{N} 2$ group, patients who received adjuvant chemotherapy with or without radiation had improved survival when compared with patients who received adjuvant radiation alone or no adjuvant therapy. In univariable analysis, the overall 5-year survival of the entire unsuspected $\mathrm{N} 2$ cohort was worse than a cohort of patients who were treated with lobectomy after induction therapy for suspected N2 (clinical N2) disease, but there was no difference in the overall survival between the 2 groups in matched analysis.
TABLE 2. Peri- and postoperative demographic and clinical characteristics

\begin{tabular}{|c|c|c|c|}
\hline & $\begin{array}{c}\text { Unsuspected } \\
\text { N2 } \\
(n=2047) \\
\end{array}$ & $\begin{array}{c}\text { Suspected } \\
\text { N2 } \\
(\mathrm{n}=\mathbf{2 3 0 2}) \\
\end{array}$ & $\begin{array}{c}P \\
\text { value* }^{*} \\
\end{array}$ \\
\hline Readmission in $30 \mathrm{~d}$ & & & $<.01$ \\
\hline Yes & $60(2.9)$ & $75(3.3)$ & \\
\hline Unknown & $1062(51.9)$ & $984(42.8)$ & \\
\hline \multicolumn{4}{|l|}{ Regional lymph nodes examined } \\
\hline $\begin{array}{l}\text { No. of patients with lymph } \\
\text { nodes examined }\end{array}$ & $2032(99.2)$ & $2112(91.7)$ & \\
\hline Median (interquartile range) & $11(6-19)$ & $8(3-19)$ & $<.01$ \\
\hline Positive lymph nodes examined & & & $<.01$ \\
\hline $\begin{array}{l}\text { No. of patients with lymph } \\
\text { nodes examined }\end{array}$ & $2033(99.2)$ & $2100(91.2)$ & \\
\hline Median (interquartile range) & $3(1-5)$ & $2(0-9)$ & \\
\hline $\begin{array}{l}\text { Surgical inpatient stay, days } \\
\text { from surgery }\end{array}$ & & & $<.01$ \\
\hline $\begin{array}{l}\text { No. of patients with } \\
\text { available data }\end{array}$ & 924 & 1176 & \\
\hline Mean \pm standard deviation & $7.9 \pm 9.0$ & $7.4 \pm 8.2$ & \\
\hline Tumor location & & & $<.01$ \\
\hline RLL & $406(19.8)$ & $331(14.4)$ & \\
\hline LLL & $263(12.9)$ & $177(7.7)$ & \\
\hline RML & $81(4.0)$ & $83(3.6)$ & \\
\hline RUL & $586(28.6)$ & $1087(47.2)$ & \\
\hline LUL & $638(31.2)$ & $536(23.3)$ & \\
\hline Other & $73(3.6)$ & $88(3.8)$ & \\
\hline Surgical margins & & & $<.01$ \\
\hline
\end{tabular}

No residual tumor

$1785(87.2) \quad 1971(85.6)$

Microscopic residual tumor

Macroscopic residual tumor

$116(5.7)$

$91(4.0)$

$55(2.7)$

$82(3.6)$

Unknown

$91(4.5)$

$158(6.9)$

Pathologic T stage

T0

$\mathrm{T} 1$

$\mathrm{T} 2$

$\mathrm{T} 3$

$\mathrm{T} 4$

IS

Unknown

Pathologic N stage

N0
N1
N2
N3

N3

Pathologic M stage

M1

$1(0.1)$

$95(4.1)$

$693(33.9) \quad 596(25.9)$

$1122(54.8) \quad 577(25.1)$

$122(6.0) \quad 108(4.7)$

$106(5.2) \quad 61(2.7)$

$0(0.0) \quad 3(0.1)$

$3(0.2) \quad 862(37.5)$

$0(0.0) \quad 630(42.1)$

$0(0.0) \quad 144(9.6)$

$2047(100.0) \quad 718(47.9)$

$0(0.0) \quad 6(0.4)$

$<.01$

30-d Mortality

$0(0.0)$

$16(0.7)$

$50(2.5) \quad 56(2.4)$

Values are presented as $\mathrm{n}(\%)$ unless otherwise noted. $R L L$, Right lower lobe; $L L L$, left lower lobe; $R M L$, right middle lobe; $R U L$, right upper lobe; $L U L$, left upper lobe; $I S$, in situ. $* P$ values provided are from Wilcoxon rank sum test on continuous variables and from $\chi^{2}$ test on categorical variables.

The 5-year overall survival of patients with unsuspected $\mathrm{N} 2$ disease of $30 \%$ in this study is within the range reported by other studies $(10 \%-40 \%))^{2,4-6,9}$ The incidence of unsuspected $\mathrm{pN} 2$ disease of $4.4 \%$ in our cohort is within 


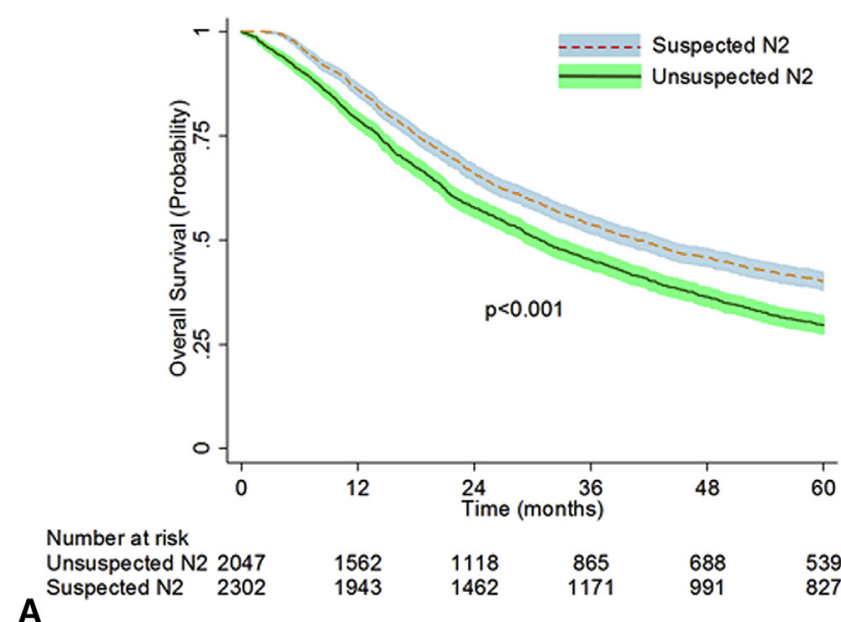

A

FIGURE 3. A, Overall survival, and B, Matched analysis based on propensity scores, of patients with unsuspected versus suspected N2 non-small cell lung cancer (NSCLC). Patients with "unsuspected N2" disease had undergone lobectomy as primary therapy for cT1-3 cN0-1 cM0 NSCLC and were found to have pN2 disease at the time of surgery. Patients with "suspected N2" disease had clinical stage IIIA N2 NSCLC who underwent induction chemotherapy with or without radiation followed by lobectomy.

but on the low side of the range previously reported by other single institution studies $(2.0 \%-18.5 \%))^{2-8}$ The NCDB does not have information on how patients were clinically staged, but presumably, given the dates of the study from 1998 to 2006, a significant percentage of patients were staged with positron emission tomography (PET) and computed tomography (CT), which may have contributed to the low incidence of unsuspected N2 disease. Studies that have reported higher incidences of unsuspected $\mathrm{pN} 2$ disease were often older ${ }^{9,11}$ and may have relied more on CT or radiograph ${ }^{2,4,5}$ alone than on PET/CT. Studies reporting lower incidences of unsuspected N2 disease $(2.9 \%-7.3 \%)$ often were from centers that used a combination of CT and PET/CT imaging. ${ }^{3,6,7}$ An important limitation regarding this study is that the NCDB does not contain details regarding mediastinal lymph node evaluation; it is unknown how many lymph node stations were evaluated and how many complete mediastinal lymph node dissections were performed. The low incidence of unsuspected $\mathrm{N} 2$ disease could also be because not all patients received comprehensive lymph node evaluation. In addition, the true incidence of unsuspected $\mathrm{N} 2$ disease in cT1-T3 cN0-N1 patients in the NCDB is likely somewhat higher than the rate of $4.4 \%$ that we observed because we realize that our analysis has not captured patients who had cT1-T3 cN0-N1 NSCLC but who were found to have a positive mediastinal lymph node by endobronchial ultrasound or mediastinoscopy and then were treated with induction therapy or definitive nonsurgical therapy. Although the scope of our study does not allow us to determine when pathologic mediastinal staging should be performed for cT1-T3 $\mathrm{cN} 0-\mathrm{cN} 1$ patients, the low incidence of unsuspected N2 disease does not necessarily suggest that there needs to be increased use of mediastinoscopy or endobronchial ultrasound in patients with T1 N0 or T2 N0 NSCLC. As noted previously, the routine use of mediastinoscopy does not greatly increase the negative predictive value of PET/CT and has poor sensitivity as a screening test. ${ }^{21}$

While the incidence of unsuspected $\mathrm{N} 2$ disease is relatively low, thoracic surgeons will likely find a clinically meaningful number of patients with unsuspected pN2 disease when undertaking thoracoscopy or thoracotomy considering the prevalence of lung cancer worldwide. Although induction chemotherapy before surgery is established as superior to primary surgery for N2 disease, ${ }^{22}$ there is uncertainty regarding the proper course of action for clinically unsuspected N2 disease. From the limited available data, previous authors have recommended continuing with resection if unsuspected $\mathrm{N} 2$ disease is diagnosed at the time of thoracotomy or thoracoscopy. ${ }^{2,6,9-11,13}$ The findings from our study suggest that continuing with planned resection with lobectomy is appropriate if a surgeon encounters unsuspected $\mathrm{pN} 2$ disease in the operating room and deems that a patient is likely to be able to tolerate adjuvant chemotherapy. The findings also suggest that surgeons do not need to routinely perform intraoperative pathologic evaluation of mediastinal nodes once they have proceeded to video-assisted thoracoscopic surgery or thoracotomy for lobectomy.

The importance of adjuvant chemotherapy in improving survival must be stressed because previous randomized trials have demonstrated a benefit to adjuvant chemotherapy for nodal disease. ${ }^{23-26}$ One potential drawback to primary resection for unsuspected $\mathrm{pN} 2$ disease is the possibility for surgical morbidity to influence the use of adjuvant 
TABLE 3. Preoperative demographic and clinical characteristics of the matched groups

\begin{tabular}{|c|c|c|c|}
\hline & $\begin{array}{c}\text { Unsuspected } \\
\text { N2 } \\
(\mathbf{n}=\mathbf{6 5 5}) \\
\end{array}$ & $\begin{array}{c}\text { Suspected } \\
\quad \mathbf{N} 2 \\
(\mathbf{n}=\mathbf{6 5 5}) \\
\end{array}$ & $\begin{array}{c}P \\
\text { value }^{*}\end{array}$ \\
\hline Patient age (y) & & & .73 \\
\hline Mean \pm standard deviation & $64.5 \pm 10.8$ & $64.8 \pm 9.0$ & \\
\hline Median (interquartile range) & $65(56-73)$ & $66(59-72)$ & \\
\hline Sex & & & .91 \\
\hline Male & $290(44.3)$ & $292(44.6)$ & \\
\hline Female & $365(55.7)$ & $363(55.4)$ & \\
\hline Race & & & .98 \\
\hline White & $574(87.6)$ & $576(87.9)$ & \\
\hline Black & $59(9.0)$ & $57(8.7)$ & \\
\hline Other & $22(3.4)$ & $22(3.4)$ & \\
\hline Charlson/Deyo score & & & .82 \\
\hline 0 & $419(64.0)$ & $430(65.7)$ & \\
\hline 1 & $185(28.2)$ & $177(27.0)$ & \\
\hline 2 & $51(7.8)$ & $48(7.3)$ & \\
\hline Insurance status & & & .61 \\
\hline Uninsured & $14(2.2)$ & $13(2.0)$ & \\
\hline Private & $282(43.5)$ & $271(42.3)$ & \\
\hline Medicare & 317 (48.9) & $326(50.9)$ & \\
\hline Medicaid & $30(4.6)$ & $22(3.4)$ & \\
\hline Other government & $5(0.8)$ & $9(1.4)$ & \\
\hline Clinical T status & & & .69 \\
\hline 1 & $269(41.1)$ & $272(41.5)$ & \\
\hline 2 & $369(56.3)$ & $361(55.1)$ & \\
\hline 3 & $17(2.6)$ & $22(3.4)$ & \\
\hline Facility type & & & .90 \\
\hline Community cancer program & $54(8.2)$ & $56(8.6)$ & \\
\hline $\begin{array}{l}\text { Comprehensive community } \\
\text { cancer program }\end{array}$ & $311(47.5)$ & $299(45.7)$ & \\
\hline Academic/research program & $285(43.5)$ & $296(45.2)$ & \\
\hline $\begin{array}{l}\text { Other specified types of } \\
\text { cancer programs }\end{array}$ & $5(0.8)$ & $4(0.6)$ & \\
\hline Histology & & & .98 \\
\hline Adenocarcinoma & $331(50.5)$ & $335(52.2)$ & \\
\hline Squamous & $152(23.2)$ & $145(22.1)$ & \\
\hline Large cell & $32(4.9)$ & $28(4.3)$ & \\
\hline Bronchioalveloar & $20(3.1)$ & $22(3.4)$ & \\
\hline Neuroendocrine & $7(1.1)$ & $6(0.9)$ & \\
\hline Other & $113(17.3)$ & $119(18.2)$ & \\
\hline
\end{tabular}

therapy. Because use of adjuvant chemotherapy with or without radiation was associated with superior survival in the unsuspected $\mathrm{pN} 2$ cohort, surgical decision making regarding unsuspected $\mathrm{pN} 2$ disease should incorporate consideration of the patient's comorbid conditions and performance status. When unsuspected $\mathrm{pN} 2$ is encountered in the operating room, surgeons should consider the likelihood that patients will tolerate resection well enough to also be able to receive adjuvant chemotherapy following lobectomy based on the patient's
TABLE 4. Peri- and postoperative demographic and clinical characteristics of the matched groups

\begin{tabular}{|c|c|c|c|}
\hline & $\begin{array}{c}\text { Unsuspected } \\
\text { N2 } \\
(\mathbf{n}=\mathbf{6 5 5})\end{array}$ & $\begin{array}{c}\text { Suspected } \\
\text { N2 } \\
(\mathbf{n}=\mathbf{6 5 5})\end{array}$ & $\begin{array}{c}P \\
\text { value* }\end{array}$ \\
\hline Readmission in $30 \mathrm{~d}$ & & & .03 \\
\hline Yes & $34(5.2)$ & $43(6.6)$ & \\
\hline Unknown & $28(4.3)$ & $42(6.4)$ & \\
\hline Regional lymph nodes examined & & & $<.01$ \\
\hline $\begin{array}{l}\text { No. of patients with lymph } \\
\text { nodes examined }\end{array}$ & 655 & 651 & \\
\hline Median (interquartile range) & $11(7-19)$ & $9(4-20)$ & \\
\hline Positive lymph nodes examined & & & $<.01$ \\
\hline $\begin{array}{l}\text { No. of patients with lymph } \\
\text { nodes examined }\end{array}$ & $650(100.0)$ & $655(100.0)$ & \\
\hline Median (interquartile range) & $3(1-5)$ & $2(0-6)$ & \\
\hline $\begin{array}{l}\text { Surgical inpatient stay, days } \\
\text { from surgery }\end{array}$ & & & .06 \\
\hline No. of patients with available data & 598 & 550 & \\
\hline Median (interquartile range) & $6(4-9)$ & $6(4-8)$ & \\
\hline
\end{tabular}

Tumor location

RLL

LLL

RML

RUL

LUL

Other

$$
\begin{array}{cc}
130(19.9) & 129(19.7) \\
75(11.5) & 73(11.2) \\
19(2.9) & 19(2.9) \\
234(35.7) & 218(33.3) \\
173(26.4) & 186(28.4) \\
24(3.7) & 30(4.6)
\end{array}
$$

Surgical margins

\section{No residual tumor}

Microscopic residual tumor

Macroscopic residual tumor Other

$582(88.9) \quad 573(87.5)$

$42(6.4) \quad 26(4.0)$

$16(2.4) \quad 25(3.8)$

$15(2.3) \quad 31(4.7)$

Pathologic T stage

T0

$\mathrm{T} 1$

$\mathrm{T} 2$

T3

T4

IS

Other

Pathologic N stage

N0
N1
N2
N3

Pathologic M stage

30-d Mortality

$\begin{array}{ccr}0(0.0) & 27(4.1) & \\ 190(29.0) & 218(33.3) & \\ 387(59.1) & 174(26.6) & \\ 38(5.8) & 16(2.4) & \\ 40(6.1) & 18(2.8) & \\ 0(0.0) & 0(0.0) & \\ 0(0.0) & 202(30.8) & \\ & & <.01 \\ 0(0.0) & 191(40.4) & \\ 0(0.0) & 55(11.6) & \\ 655(100.0) & 226(47.8) & \\ 0(0.0) & 1(0.2) & \\ 0(0.0) & 7(1.1) & <.01 \\ 12(1.8) & 17(2.6) & .35\end{array}$

Values are presented as n (\%) unless otherwise noted. $R L L$, Right upper lobe; $L L L$, left lower lobe; $R M L$, right middle lobe; $R U L$, right upper lobe; $L U L$, left upper lobe; $I S$, in situ. ${ }^{*} P$ values provided are from Wilcoxon rank sum test on continuous variables and from $\chi^{2}$ test on categorical variables.

age, comorbidities, functional status, and other relevant clinical factors.

There are several limitations to this study. First, the retrospective nature of this study allows the possibility of unobserved and therefore uncontrolled confounding or selection bias. Second, although the NCDB does contain 
the CDCC comorbidity score and although we were able to match on this variable, the NCDB does not contain data on performance status, pulmonary function tests, or specific comorbidities; thus, it is possible that patients in the suspected N2 group were healthier in ways we were not able to measure because some clinicians may not choose multimodality therapy that includes surgery if patients are believed to be at higher risk for the treatment. Third, the lack of data on recurrence and disease-free survival, as well as performance status data of patients at different time points before neoadjuvant or adjuvant therapies in the NCDB, precludes assessment of these important clinical variables. Fourth, we were not able to make a direct comparison between patients with unsuspected pN2 disease and patients who were treated with induction therapy for biopsy-proven N2 disease because the NCDB does not specifically provide pathologic staging details before or following induction therapy. Thus, there is a possibility that patients in the suspected N2 cohort did not have invasive mediastinal staging before therapy and therefore may have been overstaged. Fifth, for both cohorts, the NCDB does not have data regarding details of the clinical and pathologic staging, including details on whether biopsies were submitted for immunohistochemical staining, and therefore there may be patients in the groups who were either overstaged or understaged. Sixth, the NCDB does not contain information on how many patients were suspected to have N2 disease and were started on induction therapy and ultimately did not proceed to resection. Seventh, the NCDB does not have data on different types of unsuspected N2 disease (eg, unsuspected $\mathrm{N} 2$ disease that is identified on the final pathology report delivered several days after surgery vs unsuspected N2 disease that is discovered intraoperatively by frozen section).

Another important limitation is that we were not able to analyze the outcomes of patients who underwent surgery from 2007 onward. At the time of our analysis, long-term survival data was only available until the end of 2006. Since that time, surgical techniques, preoperative staging tests, chemotherapy, and radiation have likely improved and our findings may not be as applicable to today's practice. However, the strength of analyzing an older cohort from 1998 to 2006 is that long-term survival data were available for the patients in our study.

Finally, because there is no delineation between "bulky" versus "non-bulky" $\mathrm{N} 2$ disease and single-station versus multistation $\mathrm{N} 2$ disease in the dataset, it is not possible to determine if patients with unsuspected $\mathrm{N} 2$ disease were more likely to have single-station $\mathrm{N} 2$ disease when compared with patients in the suspected $\mathrm{N} 2$ group. However, given the results of a recent national survey regarding practice patterns for stage IIIA N2 disease, ${ }^{1}$ it is likely that patients in the suspected group did not proceed with surgery after induction therapy in the presence of extensive nodal disease.

Based on these findings and current NSCLC guidelines, it appears reasonable to proceed with lobectomy if unsuspected single-station microscopic lymph node involvement is discovered at the time of planned lobectomy. If more advanced disease is encountered, or if it appears that resection would involve pneumonectomy, the decision to proceed with resection or to conclude the procedure without resection in order to use induction therapy should be made on a case-by-case basis. If multistation macroscopic disease is discovered unexpectedly in a setting of possible pneumonectomy, proceeding with surgery is less likely to produce the best outcome, although this scenario is unlikely.

Future research on unsuspected N2 disease will be important to validate and confirm the present study's findings. National or multicenter prospective databases should aim to collect further details regarding perioperative complications, comorbidities, methods of clinical and pathologic staging, and the specific type of N2 disease (eg, microscopic vs macroscopic or single station vs multistation). Further work with more granular data will help to identify factors that will predict which group of patients with unsuspected $\mathrm{N} 2$ disease would most benefit from proceeding with lobectomy.

\section{CONCLUSIONS}

Although patients with unsuspected $\mathrm{pN} 2$ disease treated with lobectomy overall do worse than patients with cT1-T3 cN2 disease treated with induction therapy followed by lobectomy, a matched analysis showed that there is no significant difference between the overall survival of patients with unsuspected $\mathrm{pN} 2$ disease and those with suspected $\mathrm{N} 2$ disease. In addition, patients with unsuspected $\mathrm{N} 2$ disease who undergo lobectomy followed by adjuvant chemotherapy with or without radiation have superior survival when compared with patients who undergo adjuvant radiation alone or no adjuvant therapy. Thus, in the setting of unsuspected $\mathrm{pN} 2$ disease, proceeding with lobectomy is appropriate if a patient is likely able to tolerate adjuvant chemotherapy with or without radiation therapy.

\section{Conflict of Interest Statement}

T.A.D. reports consulting fees from Scanlan International, Inc, outside the submitted work. All other authors have nothing to disclose with regard to commercial support.

The data used in this study are derived from a de-identified National Cancer Database file. The American College of Surgeons and the Commission on Cancer have not verified and are not responsible for the analytic or statistical methodology employed, or the conclusions drawn from these data by the investigators. 


\section{References}

1. Ettinger DS, Akerley W, Borghaei H, Chang AC, Cheney RT, Chirleac LR, et al. Non-small cell lung cancer. J Natl Compr Canc Netw. 2012;10:1236-71.

2. De Leyn P, Schoonooghe P, Deneffe G, Van Raemdonck D, Coosemans W, Vansteenkiste J, Lerut T. Surgery for non-small cell lung cancer with unsuspected metastasis to ipsilateral mediastinal or subcarinal nodes (N2 disease). Eur J Cardiothorac Surg. 1996;10:649-54.

3. Kim HK, Choi YS, Kim J, Shim YM, Kim K. Outcomes of unexpected pathologic N1 and N2 disease after video-assisted thoracic surgery lobectomy for clinical stage I non-small cell lung cancer. J Thorac Cardiovasc Surg. 2010;140:1288-93.

4. Lee DH, Kim JB, Keum DY, Hwang I, Park CK. Long term survival of patients with unsuspected n2 disease in non-small cell lung cancer. Korean J Thorac Cardiovasc Surg. 2013;46:49-55.

5. Takizawa T, Terashima M, Koike T, Akamatsu H, Kurita Y, Yokoyama A. Mediastinal lymph node metastasis in patients with clinical stage I peripheral non-small-cell lung cancer. J Thorac Cardiovasc Surg. 1997;113:248-52.

6. Obiols C, Call S, Rami-Porta R, Trujillo-Reyes JC, Saumech R, Iglesias M, et al. Survival of patients with unsuspected pN2 non-small cell lung cancer after an accurate preoperative mediastinal staging. Ann Thorac Surg. 2014;97:957-64.

7. Cerfolio RJ, Bryant AS, Eloubeidi MA. Routine mediastinoscopy and esophageal ultrasound fine-needle aspiration in patients with non-small cell lung cancer who are clinically N2 negative: a prospective study. Chest. 2006; 130:1791-5.

8. Allen MS, Darling Ge, Pechet TT, Mitchell JD, Hernon JE, Landreneau RJ, et al. Morbidity and mortality of major pulmonary resections in patients with early-stage lung cancer: initial results of the randomized, prospective ACOSOG Z0030 trial. Ann Thorac Surg. 2006;81:1013-9; discussion 1019-20.

9. Nakanishi R, Osaki T, Nakanishi K, Yoshino I, Yoshimatsu T, Watanabe H, et al. Treatment strategy for patients with surgically discovered N2 stage IIIA non-small cell lung cancer. Ann Thorac Surg. 1997;64:342-8.

10. van Klaveren RJ, Festen J, Otten H, Cox AL, de Graaf R, Lacquet LK. Prognosis of unsuspected but completely resectable N2 non-small cell lung cancer. Ann Thorac Surg. 1993;56:300-4.

11. Cerfolio RJ, Bryant AS. Survival of patients with unsuspected N2 (stage IIIA) nonsmall-cell lung cancer. Ann Thorac Surg. 2008;86:362-6; discussion 366-7.

12. Goldstraw P, Mannam GC, Kaplan DK, Michail P. Surgical management of non-small-cell lung cancer with ipsilateral mediastinal node metastasis (N2 disease). J Thorac Cardiovasc Surg. 1994;107:19-27; discussion 27-8.

13. Detterbeck F. What to do with "Surprise" N2?: intraoperative management of patients with non-small cell lung cancer. J Thorac Oncol. 2008;3:289-302.

14. Ettinger DS, Akerley W, Borghaei H, Chang AC, Cheney RT, Chirieac R, et al. Non-small cell lung cancer, version 6.2015. J Natl Compr Canc Netw. 2015;13: 515-24.
15. Ramnath N, Dilling TJ, Harris LJ, Kim AW, Michaud GC, Balekian AA, et al. Treatment of stage III non-small cell lung cancer: diagnosis and management of lung cancer, 3rd ed: American College of Chest Physicians evidence-based clinical practice guidelines. Chest. 2013;143(5 Suppl):e314S-340.

16. Ferguson MK. Optimal management when unsuspected N2 nodal disease is identified during thoracotomy for lung cancer: cost-effectiveness analysis. J Thorac Cardiovasc Surg. 2003;126:1935-42.

17. Sher DJ, Liptay MJ, Fidler MJ. Prevalence and predictors of neoadjuvant therapy for stage IIIA non-small cell lung cancer in the National Cancer Database: importance of socioeconomic status and treating institution. Int J Radiol Oncol Biol Phys. 2014;89:303-12.

18. Greene FL, American Joint Committee on Cancer, American Cancer Society. AJCC cancer staging manual. 6th ed. New York: Springer; 2002.

19. Speicher PJ, Ganapathi AM, Englum BR, Onaitis MW, D’Amico TA, Berry MF. Survival in the elderly after pneumonectomy for early-stage non-small cell lung cancer: a comparison with nonoperative management. J Am Coll Surg. 2014;218: 439-49.

20. Licht PB, Jorgensen OD, Ladegaard L, Jakobsen E. A national study of nodal upstaging after thoracoscopic versus open lobectomy for clinical stage I lung cancer. Ann Thorac Surg. 2013;96:943-9; discussion 949-50.

21. Fernandez FG, Kozower BD, Crabtree TD, Force SD, Lau C, Pickens A, et al. Utility of mediastinoscopy in clinical stage I lung cancers at risk for occult mediastinal nodal metastases. J Thorac Cardiovasc Surg. 2015;149: 35-41. 42.e1.

22. Rosell R, Gomez-Codina J, Camps C, Javier Sanchez J, Maestre J, Padilla J, et al. Preresectional chemotherapy in stage IIIA non-small-cell lung cancer: a 7-year assessment of a randomized controlled trial. Lung Cancer. 1999;26:7-14.

23. Douillard JY, Rosell R, De Lena M, Carpagnano F, Ramlau R, GonzalesLarriba JL, et al. Adjuvant vinorelbine plus cisplatin versus observation in patients with completely resected stage IB-IIIA non-small-cell lung cancer (Adjuvant Navelbine International Trialist Association [ANITA]): a randomised controlled trial. Lancet Oncol. 2006;7:719-27.

24. Arriagada R, Bergman B, Dunant A, Le Chevalier T, Pignon JP. Cisplatin-based adjuvant chemotherapy in patients with completely resected non-small-cell lung cancer. N Engl J Med. 2004;350:351-60.

25. Winton T, Livingston R, Johnson D, Rigas J, Johnston M, Butts C, et al. Vinorelbine plus cisplatin vs. observation in resected non-small-cell lung cancer. N Engl J Med. 2005;352:2589-97.

26. Pignon JP, Tribodet H, Scagliotti GV, Douillard JY, Shepherd FA, Stephens RJ, et al. Lung adjuvant cisplatin evaluation: a pooled analysis by the LACE Collaborative Group. J Clin Oncol. 2008;26:3552-9.

Key Words: lung cancer surgery, unsuspected N2 